J. Clin. Chem. Clin. Biochem.

Vol. 19,1981 , pp. $457-463$

\title{
A Multi-Wavelength Spectrophotometric Method for the Simultaneous Determination of Five Haemoglobin Derivatives
}

\author{
By A. Zwart*, Anneke Buursma*, E. J. van Kampen**, B. Oeseburg*, P. H. W. van der Ploeg** and W. G. Zijlstra* \\ * Department of Physiology, University of Groningen \\ ** Clinical Chemical Laboratory, Diakonessen Hospital, Groningen, The Netherlands
}

(Received April 29/November 25, 1980)

Summary: A method is described by which the concentration of deoxyhaemoglobin, oxyhaemoglobin, carboxyhaemoglobin, haemiglobin and sulphaemoglobin in a human blood sample is determined by passing the haemolysate without air contact through a coarse filter and subsequently measuring the absorbance at $\lambda=500,569,577,620$ and $760 \mathrm{~nm}$. The enusuing set of equations is solved by matrix calculation with the aid of a simple computer program. The method has been tested by comparing it with conventional methods for the determination of the various haemoglobin derivatives separately.

\section{Eine Viel-Wellenlängen Methode für die simultane spektrophotometrische Bestimmung von fünf Hämoglobinderivaten}

Zusammenfassung: Eine Methode, mit der die Konzentration von Desoxyhämoglobin, Oxyhämoglobin, Carboxyhämoglobin, Hämiglobin und Sulfhämoglobin in einer Blutprobe vom Menschen bestimmt werden kann, wird beschrieben. Das Hämolysat durchläuft ohne Luftkontakt ein grobes Filter; die Absorption bei $\lambda=500,569,577,620$ und $760 \mathrm{~nm}$ wird gemessen. Der sich ergebende Satz von Gleichungen wird durch Matrizen-Berechnung mit Hilfe eines einfachen Rechnerprogramms gelöst. Die Methode wurde durch Vergleich mit konventionellen Methoden für die separate Beștimmung der verschiedenen Hämoglobinderivate geprüft.

\section{Introduction}

Numerous spectrophotometric methods have been devised for the determination of haemoglobin and its common derivatives (1). Most of these are two-wavelength methods for the analysis of two-component systems. By proper preparation of the samples and/or by judicious wavelength selection, care is taken that no more than two haemoglobin derivatives determine the absorption at the two wavelengths. In most of these methods one wavelength is chosen at a cross-over point in the absorption spectra of the two components (isosbestic wavelength), which results in a linear relationship between the ratio of the absorptions measured at the two wavelengths and the relative concentration of each of the components. The importance of this advantage, however, has diminished since simple and inexpensive calculators came into general use. So there is now little ground for adhering to the use of an isosbestic wavelength. In fact, in some cases it is even desirable not to use it.

This is, for instance, the case in measuring the oxygen saturation of blood independent of the possible presence of indocyanine green, a dye commonly used for the determination of cardiac output. The absorption maximum of indocyanine green almost coincides with the isosbestic point of deoxyhaemoglobin ( $\mathrm{Hb}$ ) and oxyhaemoglobin $\left(\mathrm{HbO}_{2}\right)$ at $\lambda=800 \mathrm{~nm}$ (fig. 1). Therefore, $\lambda=860 \mathrm{~nm}$ is used instead, thus eliminating the influence of the dye on the oxygen saturation measurement (2).

Until recently, the analysis of blood samples containing more than two haemoglobin derivatives has been much more difficult. Nevertheless, various methods have been developed, especially for the simultaneous determination of carboxyhaemoglobin ( $\mathrm{HbCO}$ ) and haemiglobin (methaemoglobin; $\mathrm{Hi})(3,4,5)$, or $\mathrm{HbCO}$, $\mathrm{Hi}$ and sulphhaemoglobin (SHb) (6). All these methods are rather cumbersome. They involve elaborate preparatory measures and the determination of correction factors or the use of special nomograms. Extensive manipulation of the blood samples is especially undesirable when $\mathrm{Hb}$ and $\mathrm{HbO}_{2}$ have to be measured in addition to one or more dyshaemoglobins ( $\mathrm{HbCO}, \mathrm{Hi}, \mathrm{SHb})(7)$, as any contact with air may cause a change in oxygenation. 

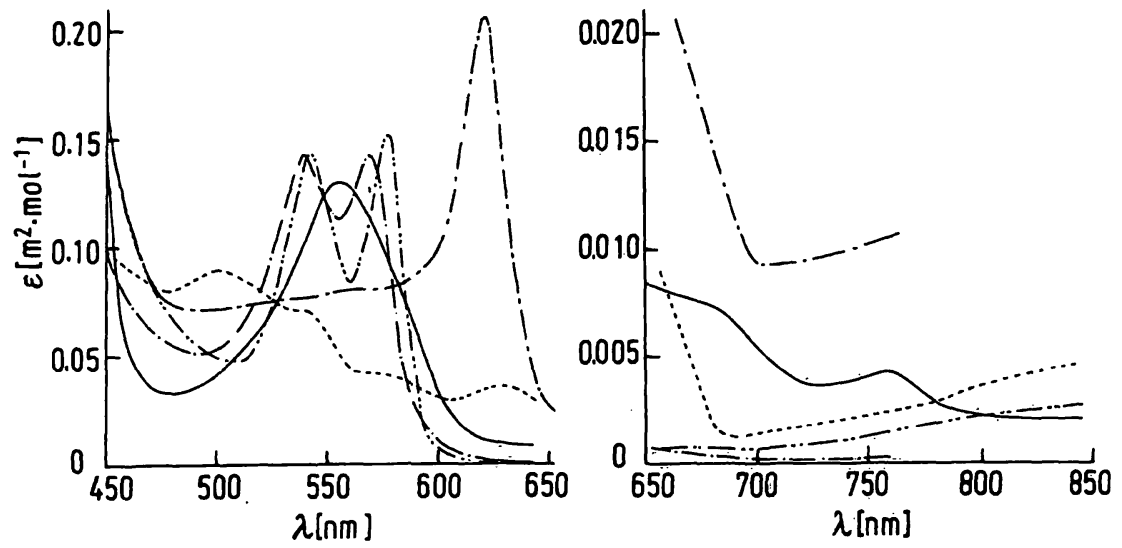

Fig. 1. Absorption spectra of $\mathrm{Hb}(-), \mathrm{HbO}_{2}(---), \mathrm{HbCO}(-.-), \mathrm{Hi}(----)(\mathrm{pH} \mathrm{7.0-7.4)}$ and $\mathrm{SHb}(---)$.

Since the lineic absorbances ${ }^{1}$ ) of most common haemoglobin derivatives are known over a wide spectral range $(8,9)$, it would seem astonishing that no straightforward multi-wavelength methods have been developed for the simultaneous determination of oxygen saturation, one or more dyshaemoglobins and total haemoglobin in human blood. The introduction of such methods, however, has for years been impeded by the fact that no practical method was available for removing all scattering particles from the haemolysate so that the lineic absorbances determined with partly purified haemoglobin solutions could be applied. Most filtering procedures appeared to need high pressures, and they resulted in a clogged filter before enough filtrate was obtained. Moreover, it was necessary to avoid any contact between sample and ambient air, or any appreciable degree of dilution of the sample, as these may cause changes in oxygenation. The application in the clinical chemical laboratory of a multi-wavelength method for the determination of haemoglobin derivatives has until recently also been impeded by the lack of a simple means of solving a set of equations with more than three unknowns. Since the absorption spectrum of SHb was not accurately known, it was also impossible to include all clinically important haemoglobin derivatives in the assay.

Easy processing of spectrophotometric data.was made possible for the clinical chemist by the advent of microcomputers and programmable calculators. The necessary data on the absorption spectrum of $\mathrm{SHb}$ is available from recent work in our laboratory (7). As a solution to the main problem, it was found that filtration through a rather coarse filter, e.g. a piece of cotton wool, removes enough scattering material from the haemolysate so that the use of the known lineic absorbances of the common haemoglobin derivatives is valid. This paper describes a five-wavelength method for the simultaneous determination of $\mathrm{Hb}, \mathrm{HbO}_{2}, \mathrm{HbCO}, \mathrm{Hi}$ and $\mathrm{SHb}$. The sum of the concentrations of the five haemoglobin derivatives proved to be equal to the total haemoglobin concentra-

1) Lineic absorption is the new, IUPAC/IFCC approved term for exctinction coefficient. tion $\left(c_{\mathrm{Hb}}^{*}\right)$ as determined with the internationally standardized haemiglobin cyanide $(\mathrm{HiCN})$ method $(10,11)$. Application of both methods to the same blood sample thus affords an opportunity for interparametric quality control (12).

\section{Methods}

If a solution contains $\boldsymbol{n}$ dissolved substances with considerable differences between their absorption spectra, this $n$-component system can be analysed by measuring at at least $n$ different wavelengths. These measurements provide $n$ equations of the type

$$
A^{\lambda}=\epsilon_{1}^{\lambda} \cdot c_{1} \cdot l+\epsilon_{2}^{\lambda} \cdot c_{2} \cdot l \ldots-\epsilon_{n}^{\lambda} \cdot c_{n} \cdot l
$$

where $A^{\lambda}=$ absorbance $\left(\log I_{o} / D\right)$ at wavelength $\lambda, \epsilon_{n}^{\lambda}=$ lineic absorbance of component $n$ at wavelength $\lambda, c_{n}=$ concentration of component $n$, and $l=$ lightpath length. The values of $c_{1}$, $c_{2}----c_{n}$ can be calculated by solving the set of equations, assuming that the values of $\epsilon_{n}^{\lambda}$ and $l$ are known.

For the simultaneous determination of $\mathrm{Hb}, \mathrm{HbC}_{2}, \mathrm{HbCO}$, $\mathrm{Hi}$ and SHb in human blood the absorbance of the haemolysate must be measured at 5 wavelengths. These wavelengths have been chosen in such a way that for each a (local) maximum is used: $\lambda=760 \mathrm{~nm}$ for $\mathrm{Hb}, \lambda=577 \mathrm{~nm}$ for $\mathrm{HbO}_{2}, \lambda=569 \mathrm{~nm}$ for HbCO, $\lambda=500 \mathrm{~nm}$ for $\mathrm{Hi}$ and $\lambda=620 \mathrm{~nm}$ for SHb. Table 1 shows tine 5-5 matrix of millimolar lineic absorbances. Most of these values have been taken from Van Assendelft (8), while $\epsilon_{\mathrm{SHb}}$ at $\lambda=500,569,577$ and $620 \mathrm{~nm}$ are taken from Dijkhuizen et al. (7). In the course of this investigation $\epsilon_{\mathrm{HbCO}}^{760}$ and $\epsilon_{\mathrm{SHb}}^{760}$ were redetermined.

The two haemoglobin derivatives that usually account for the largest part of the mixture ( $\mathrm{Hb}$ and $\mathrm{HbO}_{2}$ ) have very different lineic absorbances at $\lambda=500,569$ and $577 \mathrm{~nm}$ on the one hand and $\lambda=620$ and $760 \mathrm{~nm}$ on the other. Therefore, it proved

Tab. 1. Matrix of millimolar lineic absorbances $\epsilon$ expressed in $\mathrm{cm}^{-1} \cdot \mathrm{mmol}^{-1} \cdot 1=10^{-2} \cdot \mathrm{m}^{2} \cdot \mathrm{mol}^{-1}$ (cf. fig. 1 ).

\begin{tabular}{lrrrrr}
\hline$\lambda(\mathrm{nm})$ & \multicolumn{1}{c}{$\mathrm{Hb}$} & $\mathrm{HbO}_{2}$ & $\mathrm{HbCO}$ & $\mathrm{Hi}$ & $\mathrm{SHb}$ \\
\hline 500 & 4.09 & 5.05 & 5.35 & 9.04 & 7.20 \\
569 & 11.27 & 11.27 & 14.27 & 4.10 & 8.10 \\
577 & 9.40 & 15.37 & 10.00 & 4.10 & 8.10 \\
620 & 1.23 & 0.24 & 0.33 & 3.35 & 20.80 \\
760 & 0.43 & 0.13 & 0.03 & 0.24 & 1.04 \\
\hline
\end{tabular}

$l(\lambda=500,569,577)<0.01 \mathrm{~cm} \quad$ exactly calibrated $l(\lambda=620,760) \quad 0.2 \mathrm{~cm} \quad$ to 4 decimal-places

Italics indicate the chosen maximum of each derivative 
necessary to use two different pathlengths to keep the absorbance values within the range in which they can be measured with reasonable accuracy $(1,8)$. At $\lambda=620 \mathrm{~nm}$ and $760 \mathrm{~nm}$, $l=0.200 \mathrm{~cm}$ is adequate, whereas at $\lambda=500,569$ and $577 \mathrm{~nm}$ it is necessary to keep $l<0.010 \mathrm{~cm}$. In this investigation we actually used $l=0.007 \mathrm{~cm}$, achieved by inserting a $0.093 \mathrm{~cm}$ plan-parallel glass plate (Hellma Benelux, The Hague, The Netherlands) into a $0.100 \mathrm{~cm}$ cuvettc (fig. 2). The values of $l$ were checked by measuring the absorbance at $\lambda=540 \mathrm{~nm}$ of $\mathrm{HiCN}$ solutions of known concentration (13).
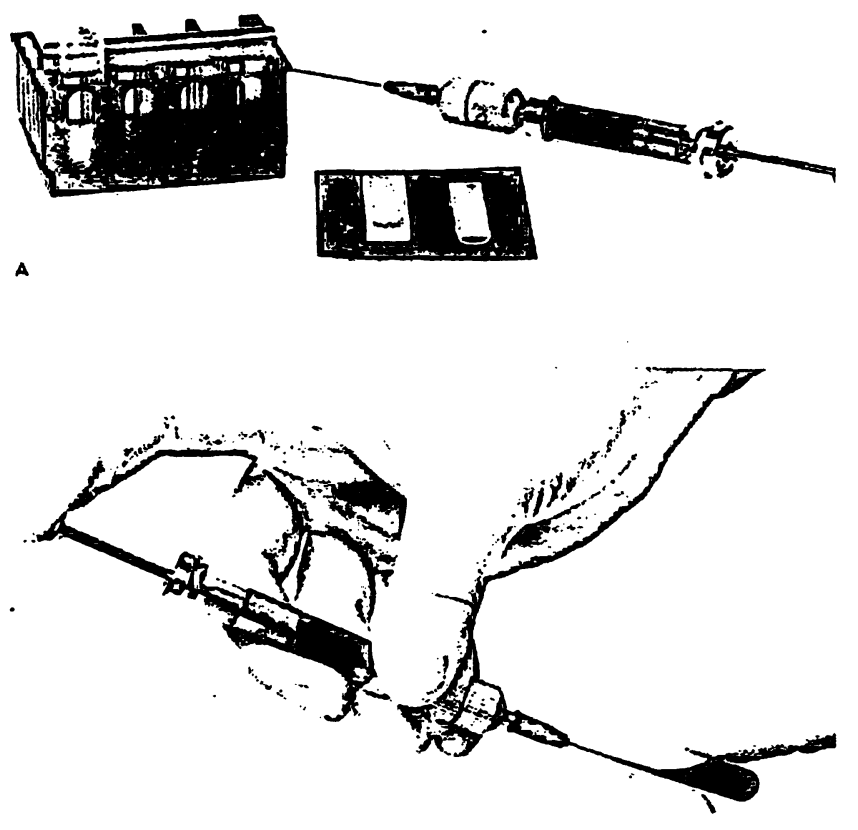

B

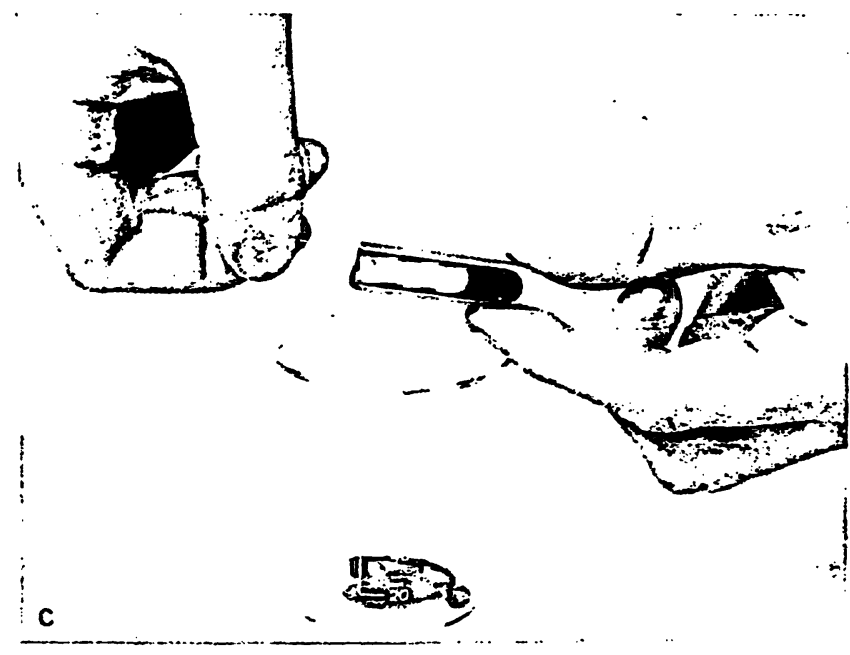

Fig. 2. Filling a $0.100 \mathrm{~cm}$ cuvette and inserting a $0.093 \mathrm{~cm}$ planparallel glass plate. Cuvettes and glass inserts are stored in a chromic acid solution, rinsed before use with demineralized water followed by acetone and dried with an air jet. The filter unit between syringe and needle contains cotton wool. The filter unit is cleaned, dried and filled with new cotton wool before each determination.

A. Cuvette holder with reference cuvette, cuvette, glass insert and $2 \mathrm{ml}$ syringe with filter and needle, containing the haemolyzed blood.

B. After discarding the first 10 drops the haemolysate is gently pressed through the filter into the cuvette.

C. The plan-parallel glass plate is inserted into the cuvette, leaving a lightpath length of $0.007 \mathrm{~cm}$.

\section{Procedures}

\section{Five-wavelength method}

All measurcments were made with freshly drawn, heparinized blood samples from apparently healthy humans of both sexes. The sample was transferred without any contact with air to a $2 \mathrm{ml}$ glass syringe containing a mixing ball $(\phi=5 \mathrm{~mm})$ and with its dead space filled with a $5 \%$ solution of the non-ionic detergent Sterox SE (Hartman-Leddon Comp., Philadelphia, Pa., USA). After thouroughly mixing blood and detergent solution, a filter unit containing a piece of cotton wool was put on the syringe. After discarding the first 10 drops to flush the needle and filter space, the two cuvettes $(l=0.200$ and $0.100 \mathrm{~cm})$ were filled with the haemolysate, and the plan-parallel glass plate was inserted into the $0.100 \mathrm{~cm}$ cuvette (fig. 2). The absorbances were measured at $\lambda=500,569,577,620$ and $760 \mathrm{~nm}$ with an Optica CF 4 grating spectrophotometer against similar cuvettes filled with distilled water in the reference channel. The spectral band width was less than $1 \mathrm{~nm}$. The wavelength calibration was checked with the aid of mercury emission lines and the absorbance calibration with the aid of a carbon yellow filter (Corning HT yellow 0-10; NBS test $1784730-10$ ). The concentrations of the haemoglobin derivatives were calculated from the absorbance values by natrix calculation using a desk top calculator (HP 9845 A; cf. Appendix). The slight differences between the cuvettes in the measuring channel and the reference channel and the dilution of the sample with Sterox SE solution were taken into account. The concentrations of the various components were calculated both in $\mathrm{mmol} \cdot \mathrm{l}^{-1}$ and as a fraction of total haemoglobin. In addition, the oxygen saturation

$$
S_{\mathrm{O}_{2}}=\frac{c_{\mathrm{HbO}_{2}}}{c_{\mathrm{HbO}_{2}}+c_{\mathrm{Hb}}}
$$

was calculated, and the concentrations of the components were added to obtain a value for $c_{\mathrm{Hb}}^{*}$.

\section{Preparation of blood samples containing various haemoglobin derivatives}

For testing the five-wavelength method, samples with different amounts of the various haemoglobin derivatives were prepared. As the conventional methods for measuring these derivatives, except for the determination of $\mathrm{Hi}$, are based on the assumption that not more than two components are present, the test samples were prepared accordingly. Blood with different ratios of $\mathrm{HbO}_{2}$ and $\mathrm{Hb}$ was prepared by tonometry with humidified $\mathrm{O}_{2} / \mathrm{N}_{2}$ mixtures containing $5.6 \% \mathrm{CO}_{2}$ in a stainless steel chamber with a magnetic stirrer at the bottom. The gases were fed into the tonometer through ports in the perspex lid and the $\mathrm{O}_{2} / \mathrm{N}_{2}$ ratio was adjusted by means of needle valves (14).

Blood with different ratios of $\mathrm{HbCO}$ and $\mathrm{HbO}_{2}$ was prepared in the following way. A blood sample was divided into two parts. One part was oxygenated by tonometry with humidified pure $\mathrm{O}_{2}$ for $30 \mathrm{~min}$, vielding practically $100 \% \mathrm{HbO}_{2}$. The other part was subjected to tonometry with humidified pure $\mathrm{CO}$ for $15 \mathrm{~min}$, followed by $5 \% \mathrm{CO}$ and $95 \% \mathrm{O}_{2}$ for $15 \mathrm{~min}$. This procedure yields more than $90 \% \mathrm{HbCO}$, the remainder being $\mathrm{HbO}_{2}$. Samples with different $\mathrm{HbCO}$ fractions were then made by mixing various volumes from the two syringes in which the blood was kept after tonometry.

To prepare blood samples with various amounts of $\mathrm{Hi}$, blood was haemolyzed by the addition of one drop of undiluted Sterox SE and distributed to several test tubes to which various volumes of a $90 \mathrm{mmol} \cdot 1^{-1} \mathrm{~K}_{3} \mathrm{Fe}(\mathrm{CN})_{6}$ solution were added. The tubes were kept for $90 \mathrm{~min}$ at room temperature before the samples were measured.

Blood containing SHb was prepared according to Siggaard-Andersen et al. (6). First, the blood was fully oxygenated by tonometry with humidified pure $\mathrm{O}_{2}$ for $2 \mathrm{~h}$. One half of the oxygenated blood was centrifuged and the packed cells incubated for $30 \mathrm{~min}$ with an equal volume of a freshly prepared solution of $\mathrm{Na}_{2} \mathrm{~S}$ and $\mathrm{HCl}\left(50\right.$ and $75 \mathrm{mmol} \cdot 1^{-1}$, respectively; $\mathrm{pH} \approx 7.5$ ). Next, excess $\mathrm{H}_{2} \mathrm{~S}$ was removed by tonometry with humidified pure $\mathrm{O}_{2}$ for $30 \mathrm{~min}$ and the blood, now containing $15-25 \%$ 
$\mathrm{SHb}$, was stored in a gas-tight syringe. The other half of the oxygenated blood was also stored in a syringe and samples with different $\mathrm{SHb}$ content were prepared by mixing various volumes from the two syringes.

Blood samples differing in total haemoglobin concentration were prepared by separating ery throcytes and plasma from a certain amount of blood and again mixing these components in different ratios.

\section{Conventional methods}

When a two-component system is analysed by measuring at two wavelengths, one of which is isosbestic for the two components, it follows from the two equations of the type of Eq. 1 with $n=2$, that

$$
\frac{c_{1}}{c_{1}+c_{2}}=a \frac{A^{\lambda^{1}}}{A^{\lambda^{2}}+b}
$$

where $a$ and $b$ are constants and $\lambda^{2}$ is the isosbestic wavelength (1). When the two components are $\mathrm{Hb}$ and $\mathrm{HbO}_{2}$, it follows from Eqs. (2) and (3), that

$$
S_{\mathrm{O}_{2}}=a \frac{A^{\lambda^{1}}}{A^{\lambda^{2}}}+b
$$

$a$ and $b$ can be determined by measuring $A^{\lambda^{1}} / A^{\lambda^{2}}$ for some fully oxygenated $\left(S_{\mathrm{O}_{2}}=1\right)$ and some completely deoxygenated $\left(S_{\mathrm{O}_{2}}=0\right)$ blood samples. Suitable wavelengths for the determination of $S_{\mathrm{O}_{2}}$ are $\lambda=680$ and $800 \mathrm{~nm}$. At the isosbestic point $(\lambda=800 \mathrm{~nm})$ the absorption spectra of $\mathrm{Hb}$ and $\mathrm{HbO}_{2}$ are rather flat (2) and $\lambda=680 \mathrm{~nm}$ is in the range of maximum spectral sensitivity for the determination of $S_{\mathrm{O}_{2}}$ (15). Measurement of blood from 6 humans and 8 dogs gave $a=-0.3819$ and $b=1.1633$ (2). For each measurement $2 \mathrm{ml}$ blood was transferred anaerobically to a $2 \mathrm{ml}$ syringe containing a glass ball $(\phi=5 \mathrm{~mm})$ for mixing and with its dead space filled with a $5 \%$ Sterox SE solution. After thoroughly mixing the sample and discarding the first drops, the sample was injected into a planparallel glass cuvette with $l=0.200 \mathrm{~cm} . A^{680}$ and $A^{800}$ were measured using an Optica CF4 grating spectrophotometer with an effective band width $<1 \mathrm{~nm}$. $\mathrm{S}_{\mathrm{O}_{2}}$ was calculated with the aid of Eq. 5

$$
S_{\mathrm{O}_{2}}=1.1633-0.3819 \frac{A^{680}}{A^{800}}
$$

For the determination of the $\mathrm{HbCO}$ fraction in the samples containing $\mathrm{HbCO}$ and $\mathrm{HbO}_{2}$ a similar method was used. The wavelengths selected for this determination were $\lambda=562$ and $540 \mathrm{~nm}$, the latter being isosbestic. The measurements were carried out with $l=0.007 \mathrm{~cm}$ (fig. 2). The constants of Eq. 6 have been determined by calibration against a titrimetric method for $\mathrm{HbCO}$ in blood (16).

$$
\frac{c_{\mathrm{HbCO}}}{c_{\mathrm{HbCO}}+c_{\mathrm{HbO}_{2}}}=3.215 \frac{A^{562}}{A^{540}}-1.923 .
$$

The Hi fraction in the test samples was determined with a KCN addition method $(1,7,17)$. Four reagent solutions were used. Solution 1 contained $0.05 \%$ Sterox SE and a phosphate buffer (27.50 mmol $\cdot l^{-1} \mathrm{Na}_{2} \mathrm{HPO}_{4}$ and $13.16 \mathrm{mmol} \cdot{ }^{-1} \mathrm{KH}_{2} \mathrm{PO}_{4}$; $\mathrm{pH}=7.4)$. Solutions 2 and 3 contained in addition $3.84 \mathrm{mmol}$. $\mathrm{l}^{-1} \mathrm{KCN}$ and $3.04 \mathrm{mmol} \cdot \mathrm{1}^{-1} \mathrm{~K}_{3} \mathrm{Fe}(\mathrm{CN})_{6}$, respectively. Solution 4 contained in addition $3.84 \mathrm{mmol} \cdot \mathrm{I}^{-1} \mathrm{KCN}$ as well as $3.04 \mathrm{mmol} \cdot \mathrm{-}^{-1} \mathrm{~K}_{3} \mathrm{Fe}(\mathrm{CN})_{6} .0 .5 \mathrm{ml}$ blood was added to $25 \mathrm{ml}$ of each of the four solutions. In the second solution all $\mathrm{Hi}$ present becomes converted into HiCN. In the third and the fourth solution all haemoglobin present is converted into $\mathrm{Hi}$ and $\mathrm{HiCN}$, respectively. The absorbance of the four solutions was measured at $\lambda=630 \mathrm{~nm}$ (Optica CF4) with either $l=1.00 \mathrm{~cm}$ or $l=4.00 \mathrm{~cm}$ according to the absorbance level. The Hi fraction was calculated with the aid of Eq. 7 .

$$
\frac{c_{\mathrm{Hi}}}{c_{\mathrm{Hb}}^{*}}=\frac{A_{1}-A_{2}}{\dot{A}_{3}-A_{4}}
$$

where $A_{1}, A_{2}, A_{3}$ and $A_{4}$ represent the absorbances at $\lambda=630 \mathrm{~nm}$ of the four blood reagent mixtures and $c_{\mathrm{Hb}}^{*}$ is the total haemoglobin concentration.

$\mathrm{SHb}$ was determined by means of the following procedure. $0.5 \mathrm{ml}$ blood was added to $25 \mathrm{ml}$ of a solution containing $0.05 \%$ Sterox SE and a phosphate buffer $\left(27.50 \mathrm{mmol} \cdot 1^{-1} \mathrm{Na}_{2} \mathrm{HPO}_{4}\right.$ and $\left.13.16 \mathrm{mmol} \cdot 1^{-1} \mathrm{KH}_{2} \mathrm{PO}_{4} ; \mathrm{pH}=7.4\right)$. The absorbance of this solution was measured at $\lambda=620 \mathrm{~nm}$ (Optica CF4) with either $l=1.00 \mathrm{~cm}$ or $l=4.00 \mathrm{~cm}$ according to the absorbance level. This one-wavelength method allows the calculation of the $\mathrm{SHb}$ fraction only when an appiopriate correction is made for the absorbance of the other component present, i.e. $\mathrm{HbO}_{2}$ (Hi was excluded in all samples measured). This correction has been included in the equation for calculating $\mathrm{SHb}$.

$$
\frac{c_{\mathrm{SHb}}}{c_{\mathrm{Hb}}^{*}}=\frac{A^{620}}{c^{\prime} \cdot l \cdot\left(\epsilon_{\mathrm{SHb}}^{620}-\epsilon_{\mathrm{HbO}_{2}}^{620}\right)}-\frac{\epsilon_{\mathrm{HbO}_{2}}^{620}}{\epsilon_{\mathrm{SHb}}^{620}-\epsilon_{\mathrm{HbO}}^{620}}
$$

where $c^{\prime}$ represents the total haemoglobin concentration of the diluted blood in $\mathrm{mmol} \cdot \mathrm{I}^{-1}$, and $\epsilon_{\mathrm{SHb}}^{620}$ and $\epsilon_{\mathrm{HbO}}^{620}$ are the millimolar lineic absorbances of $\mathrm{SHb}$ and $\mathrm{HbO}_{2}$ at $\lambda=620 \mathrm{~nm}$ (table 1).

The total haemoglobin concentration of the test samples was determined as HiCN in conformity with the recommendations of ICSH (11).

\section{Results}

Figure 3 shows the results of 22 comparative determinations of $S_{\mathrm{O}_{2}}$ with the five-wavelength method and the $680 / 800$ method. The systematic differences of the fivewavelength method with respect to the $680 / 800$ method was $1.2 \% \mathrm{~S}_{\mathrm{O}_{2}}$ with a standard deviation of $2.3 \% \mathrm{~S}_{\mathrm{O}_{2}}$. The results of 32 comparative measurements of the $\mathrm{HbCO}$ fraction with the five-wavelength method and the $562 / 540$ method are shown in figure 4 . The systematic difference of the five-wavelength method with respect to

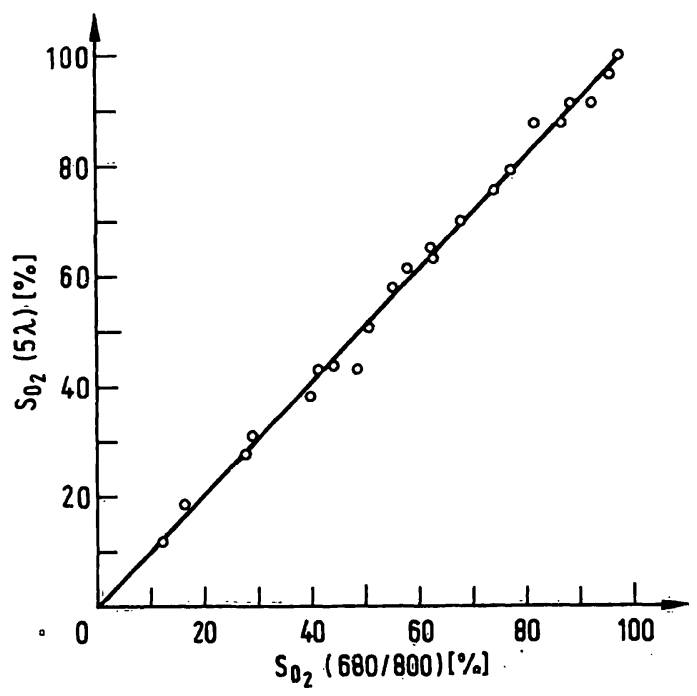

Fig. 3. $S_{\mathrm{O}_{2}}(5 \lambda)$ plotted against $S_{\mathrm{O}_{2}}(680 / 800)$ for 22 blood samples from 3 healthy humans. Regression equation: $S_{\mathrm{O}_{2}}(5 \lambda)=1.03 \times S_{\mathrm{O}_{2}}(680 / 800)-0.32$. Correlation coefficient: 0.993 . 


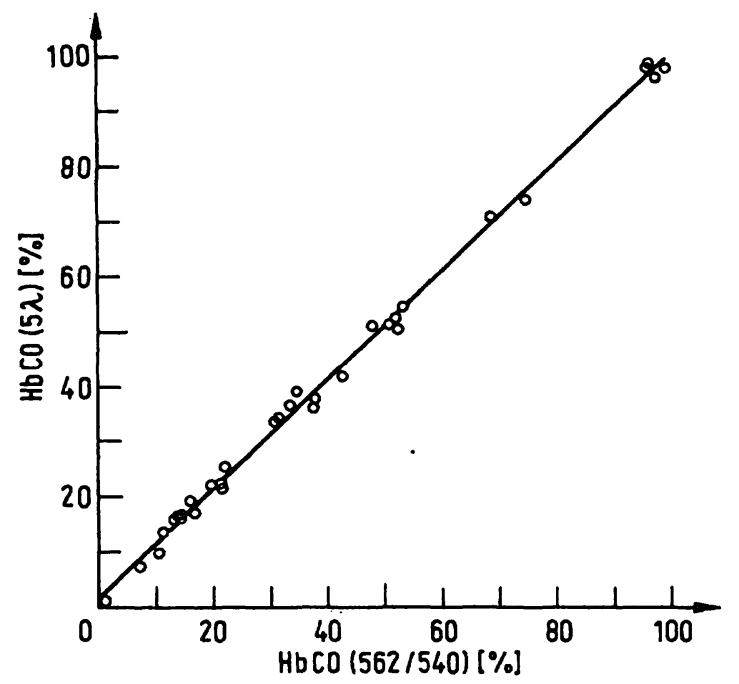

Fig. 4. HbCO (5 $\lambda)$ plotted against HbCO $(562 / 540)$ for 32 blood samples from 7 healthy humans. Regression equation: $\% \mathrm{HbCO}(5 \lambda)=0.99 \times \% \mathrm{HbCO}(562 / 540)+1.45$ Correlation coefficient: 0.996 .

the $562 / 540$ method was $1.2 \% \mathrm{HbCO}$ with a standard deviation of $1.7 \% \mathrm{HbCO}$. Figure 5 shows the results of 16 comparative measurements of the Hi fraction with the five-wavelength method and the $\mathrm{KCN}$ addition method. The systematic difference of the five-wavelength method with respect to the $\mathrm{KCN}$ addition method was $-0.4 \% \mathrm{Hi}$ with a standard deviation of $0.7 \% \mathrm{Hi}$. Eight comparative measurements of the SHb fraction with the five-wavelength method and the 620 method are shown in figure 6 . The systematic difference of the fivewavelength method with respect to the 620 method was $-0.6 \% \mathrm{SHb}$ with a standard deviation of $0.2 \% \mathrm{SHb}$. Figure 7 shows the relationship between $c_{\mathrm{Hb}}^{*}$ as determined by adding the concentrations of all haemoglobin derivatives present in the sample (five-wavelength method) and $c_{\mathrm{Hb}}^{*}$ as determined by the HiCN method.

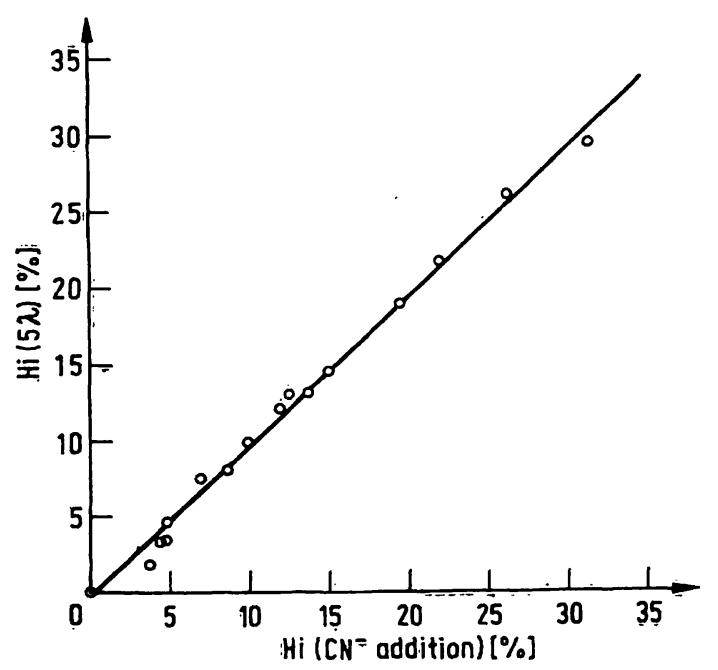

Fig. 5. Hi (5 $\lambda)$ plotted against Hi ( $K C N$ addition method) for 16 blood samples from 4 heal thy humans. Regression equation: \% Hi $(5 \lambda)=0.99 \times \% \mathrm{Hi}(\mathrm{KCN})-0.31$. Correlation coeffịcient: 0.994 .

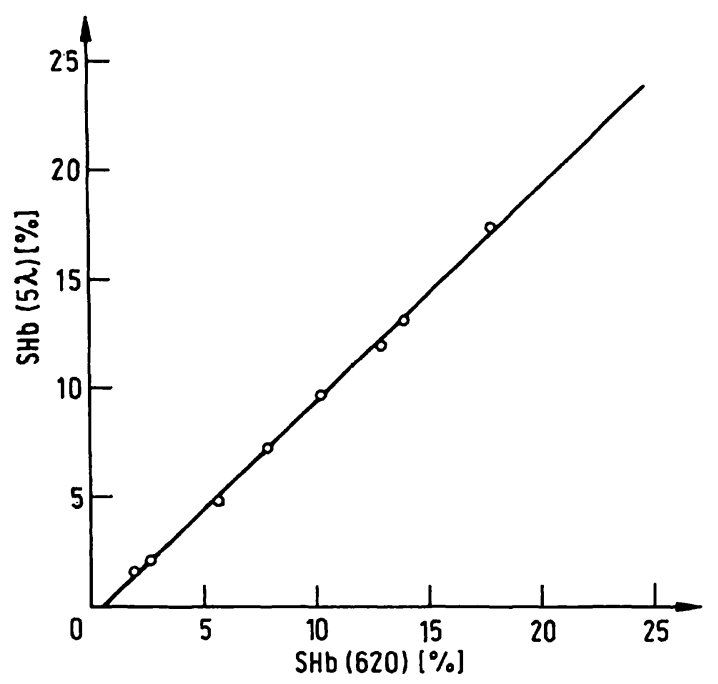

Fig. 6. SHb (5 $\lambda$ ) plotted against SHb (620) for 2 blood samples from a healthy human. Regression equation: \% SHb $(5 \lambda)=0.99 \times \%$ SHb $(620)-0.52$. Correlation coefficient: 0.998 .

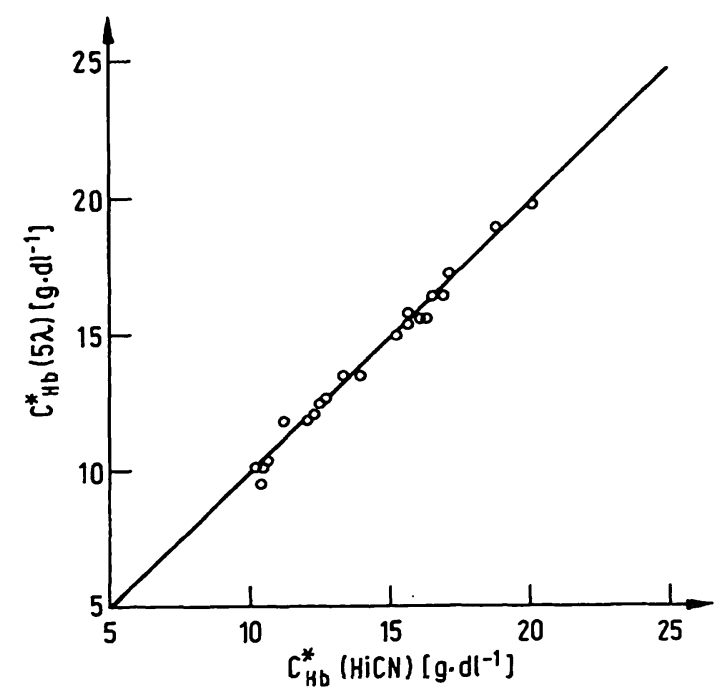

Fig. 7. $c_{\mathrm{Hb}}^{*}(5 \lambda)$ plotted against $c_{\mathrm{Hb}}^{*}(\mathrm{HiCN})$ for 22 blood samples of 5 healthy humans. Regression equation: $c_{\mathrm{Hb}}^{*}(5 \lambda)=1.00 c_{\mathrm{Hb}}^{*}(\mathrm{HiCN})-0.07$. Correlation coefficient: 0.988 .

The systematic difference of the five-wavelength method with respect to the $\mathrm{HiCN}$ method was $-0.06 \mathrm{~g} \cdot \mathrm{dl}^{-1}$ with a standard deviation of $0.15 \mathrm{~g} \cdot \mathrm{dl}^{-1}(n=22)$.

\section{Discussion}

This method for the simultaneous determination of 5 haemoglobin derivatives was developed following the observation that by simple filtration through cotton wool scattering particles can be removed from a haemolysate to such a degree that the lineic absorbances as determined for partly purified haemoglobin solutions can be applied. All methods hitherto used for clearing haemolysates were too complicated and time-consuming and could hardly be carried out without air-contact, a condi- 
tion which is essential for the accurate measurement of oxygen saturation. For the same reason any significant degree of dilution of the blood with a reagent solution had to be omitted. The small filter unit used in this investigation offers only slight resistance to flow and does not interfere with the filling of the cuvettes. Yet, the ensuing haemoglobin solutions are clear enough for the application of Lambert-Beer's law and the known lineic absorbances. The method has not yet been tested for blood with pathological plasma protein patterns. In such cases, for the time being, it should be applied with caution. The dilution of the sample with $5 \%$ Sterox SE solution is so slight that even when the oxygen saturation is near zero and the Sterox SE solution is in equilibrium with air the ensuing change in oxygen saturation will be less than $0.5 \%$.

Wavelength and lightpath length are the most critical factors for the validity of the five-wavelength method. The wavelength scale of the spectrophotometer should therefore be checked regularly. This is most easily done with the aid of mercury emission lines. A small spectral band width $(<1 \mathrm{~nm})$ should be used and in each determination all wavelengths should be adjusted carefully. The lightpath length of the cuvettes should be determined by comparative measurements with a calibrated $1 \mathrm{~cm}$ cuvette using various concentrations of a substance exactly obeying Lambert-Beer's law. HiCN solutions prepared in the same way as the International Reference Solution (13) are suitable for this purpose. Checking the absorbance scale with a filter of exactly known absorbance is recommendable, though not strictly necessary when a modern spectrophotometer is used.

Figures 3-6 show that the various haemoglobin derivatives can be accurately determined by means of the fivewavelength method. An objection which can be raised against the applied testing procedure is that the test samples usually contained only two haemoglobin derivatives. This was a consequence of the fact that the methods used for comparison, except for the determination of $\mathrm{Hi}$, could only be applied to two-component systems. However, it should be noted that the five-wavelength method correctly indicated zero concentration for the components not present in the sample, which certainly is indicative of the validity of the method.

As shown in figure 5, the comparative measurements of Hi have been limited to the $0-30 \%$ range. We were forced to do so, because the KCN addition method progressively overestimates the Hi concentrations of samples containing $>30 \% \mathrm{Hi}$. Some additional dilution experiments indicated that the five-wavelength method gives correct values for the $\mathrm{Hi}$ fraction at least up to $80 \%$. The comparative measurements of SHb had to be limited to the 0-25\% range, because test samples with more than $25 \%$ SHb can hardly be obtained with the technique used. In spite of these limitations, the results shown in figures 5 and 6 for $\mathrm{Hi}$ and SHb, respectively, amply cover the clinically relevant rangè.

It may be regarded as a distinct advantage of the fivewavelength method that it allows the simultaneous determination of $\mathrm{Hi}$ and $\mathrm{SHb}$, which is of special interest in toxicological cases. Although the $\mathrm{KCN}$ addition method has originally been introduced as part of a determination of Hi and SHb in a single sample of blood (17), it has recently been shown that the presence of SHb results in an appreciable overestimation of the Hi fraction by this method (7).

If no other haemoglobin derivatives are present, the sum of the concentrations as determined by the five-wavelength method should be equal to $c_{\mathrm{Hb}}^{*}$. This is beautifully borne out by the data of figure 7: the regression line is indistinguishable from the line of identity. These results could be obtained in spite of the fact that the reagent solution used in the $\mathrm{HiCN}$ method converts $\mathrm{SHb}$ into $\mathrm{SHiCN}$ instead of into $\mathrm{HiCN}$. However, the error thus introduced is but slight (7). The fact that $c_{\mathrm{Hb}}^{*}$ (fivewavelength) equals $c_{\mathrm{Hb}}^{*}(\mathrm{HiCN})$ offers an easy opportunity for applying interparametric quality control (12). It will be sound practice to supplement each determination of haemoglobin derivatives by means of the five-wavelength method with a determination of $c_{\mathrm{Hb}}^{*}(\mathrm{HiCN})$.

As shown in figure 1 and table 1 the set of wavelengths chosen for the five-wavelength method contains for each haemoglobin derivative a local maximum. The use of $\lambda=760 \mathrm{~nm}$ for $\mathrm{Hb}$ at first sight seems rather curious, $\lambda=555 \mathrm{~nm}$ being the obvious choice. In fact we did try to use $\lambda=555 \mathrm{~nm}$ instead of $\lambda=760 \mathrm{~nm}$. This also has the advantage that a spectrophotometer without a redsensitive photo-tube can be used. However, less accurate results were obtained when the $555 \mathrm{~nm}$ maximum of $\mathrm{Hb}$ was used. This was especially so in the determination of the $\mathrm{HbO}_{2}$ and $\mathrm{HbCO}$ fractions. A possible explanation for this might be the rather small differences between $\epsilon_{\mathrm{Hb}}, \epsilon_{\mathrm{HbO}_{2}}$ and $\epsilon_{\mathrm{HbCO}}$ at $\lambda=555$ and $569 \mathrm{~nm}$. However, the experiments clearly demonstrate that $\lambda=760 \mathrm{~nm}$ is to be preferred as the wavelength for measurements.

\section{Appendix}

10 ! The file-name is 5 lambda

20 OPTION BASE 1

30 DIM Len (5), Abs (5), Con (5), Eps $(5,5)$

40 MAT READ Eps, Len

50 DATA 4.09, 5.05, 5.35, 9.04, 7.2

60 DATA $11.27,11.27,14.27,4.1,8.1$

70 DATA $9.4,15.37,10.0,4.1,8.1$

80 DATA $1.23, .24, .33,3.35,20.8$

90 DATA .43,.13,.03,.24, 1.04

100 DATA $.0071, .0071, .0071, .2013, .2013$ ! Own calibrated values

110 FOR $I=1$ to 5

120 FOR $\mathrm{J}=1$ to 5

$130 \operatorname{Eps}(I, J)=\operatorname{Eps}(I, J) * \operatorname{Len}(I)$

140 NEXT J

150 NEXT I

160 MAT Eps = INV (Eps) 
170 PRINT "The absorbances please"

180 MAT INPUT Abs

190 MAT Con $=$ Eps $*$ Abs

200 Sum $=$ SUM (Con) $*$ Df $!$ Dilution-factor of syringe filled with Sterox SE

210 PRINT "SO2 \% = "; $100 *$ Con (2)/(Con (1) + Con (2))
220 PRINT "HbCO \% = "; $100 *$ Con (3) / SUM (Con)

230 PRINT "Hi $\%=" ; 100 *$ Con (4) / SUM (Con)

240 PRINT "SHb \% = "; $100 *$ Con (5) / SUM (Con)

250 PRINT "C $* \mathrm{Hb}(\mathrm{g} / \mathrm{dl})=$ "; Sum $* 1.61145$

260 END

\section{References}

1. Van Kampen, E. J. \& Zijlstra, W. G. (1965), in Advances in Clinical Chemistry (Sobotka, H. \& Stewart, C. P., eds.) Vol. 8, 141-187, Academic Press, New York/London.

2. Mook, G. A., Buursma, A., Gerding, A., Kwant, G. \& Zijlstra, W. G. (1979), Cardiovasc. Res. 13, 233-237.

3. Zijlstra, W. G. \& Muller, C. J. (1957), Clin. Chim. Acta 2, $237-245$.

4. Small, K. A., Radford, E. P., Frazier, J. M., Rodkey, F. L. \& Collison, H. A. (1971), J. Appl. Physiol. 31, 154-160.

5. Rodkey, F. L., Hill, T. A., Pitts, L. L. \& Robertson, R. F. (1979), Clin. Chem. 25, 1388-1393.

6. Siggaard-Andersen, O., N $\phi$ rgaard-Pedersen, B. \& Rem, J. (1972), Clin. Chim. Acta 42, 85-100.

7. Dijkhuizen, P., Buursma, A., Gerding, A. M. \& Zijlstra, W. G. (1977), Clin. Chim. Acta 78, 479-487.

8. Van Assendelft, O. W. (1970), Spectrophotometry of Haemoglobin Derivatives, Van Gorcum and Comp., Assen, The Netherlands.
9. Van Assendelft, O. W. \& Zijlstra, W. G. (1975), Anal. Biochem. 69, 43-48.

10. Van Kampen, E. J. \& Zijlstra, W. G. (1961), Clin. Chim. Acta 6, 538-544.

11. International Committec for Standardization in Haematology (1978), J. Clin. Pathol. 31, 139-143.

12. Van Kampen, E. J. (1978), in New Pathways in Laboratory Medicine (Rosalki, S. B., ed.), 132-140, Hans Huber Publishers, Bern/Stuttgart/Vienna.

13. Zijlstra, W. G. \& Van Kampen, E. J. (1962), Clin. Chim. Acta 7, 96-99.

14. Oeseburg, B. (1979), Crit. Care Med. 7, 396-398.

15. Mook, G. A., Van Assendelft, O. W. \& Zijlstra, W. G. (1969), Clin. Chim. Acta 26, 170-173.

16. Dijkhuizen, P., Buursma, A., Gerding, A. M., Van Kampen, E. J. \& Zijlstra, W. G. (1977), Clin. Chim. Acta 80, 95-104.

17. Evelyn, K. A. \& Malloy, H. T. (1938), J. Biol. Chem. 126, 655-662.
Prof. dr. W. G. Zijlstra Department of Physiology University of Groningen Bloemsingel 10 NL-9712 KZ Groningen The Netherlands 
